\title{
TARGET ENCLOSURE AND SYSTEM DESIGN FOR A MERCURY-TARGET NEUTRINO PRODUCING FACILITY
}

\author{
P. T. Spampinato, J. B. Chesser, D. L. Conner, T. A. Gabriel, F. X. Gallmeier, \\ J. R. Haines, and T. J. McManamy, ORNL, Oak Ridge, TN 37831-6305, USA
}

\section{Abstract}

A conceptual design for a neutrino producing facility has been developed based on a mercury jet target that interacts with a $24 \mathrm{GeV}, 1 \mathrm{MW}$ proton beam. The facility consists of a target region where pions and muons are produced, a crane hall, and hot cells for radioactive component handling. The major components include the target containment system, a high magnetic field target solenoid region, a beam absorber, a low-field solenoid decay channel, and steel and concrete radiation shielding. The design was based in part, on meeting a system operating availability of $10^{7} \mathrm{sec} / \mathrm{yr}$, and on remotely replacing lifelimited components that are exposed to neutron and gamma radiation damage.

\section{INTRODUCTION}

This paper summarizes the target facility design work that was done for the Muon Collider/Neutrino Factory Collaboration, Feasibility Study II [1]. The Target Support Facility consists of the target region and decay channel, a crane hall over the length of the facility, a maintenance cell at the ground floor level for handling magnet components, a hot cell at the tunnel level for mercury target system components, and various remote handling equipment used for maintenance tasks. This arrangement was partly based on the Muon Collider/ Neutrino Factory Collaboration, Feasibility Study I [2,3]. The facility is bounded by the proton beam window at the upstream end and the first induction linear accelerator at the downstream end. It contains the equipment for the mercury-jet target, high-field resistive and superconducting solenoids, low-field superconducting solenoids, watercooled shielding to limit radiation dose and neutron heating to the coils, biological shielding to protect personnel and the environment, and a 50-ton crane used for initial assembly and installation of major components, and subsequent maintenance activities. The target support facility is 12-m wide, and approximately 40-m long. Figure 1 is a cutaway view of the overall facility.

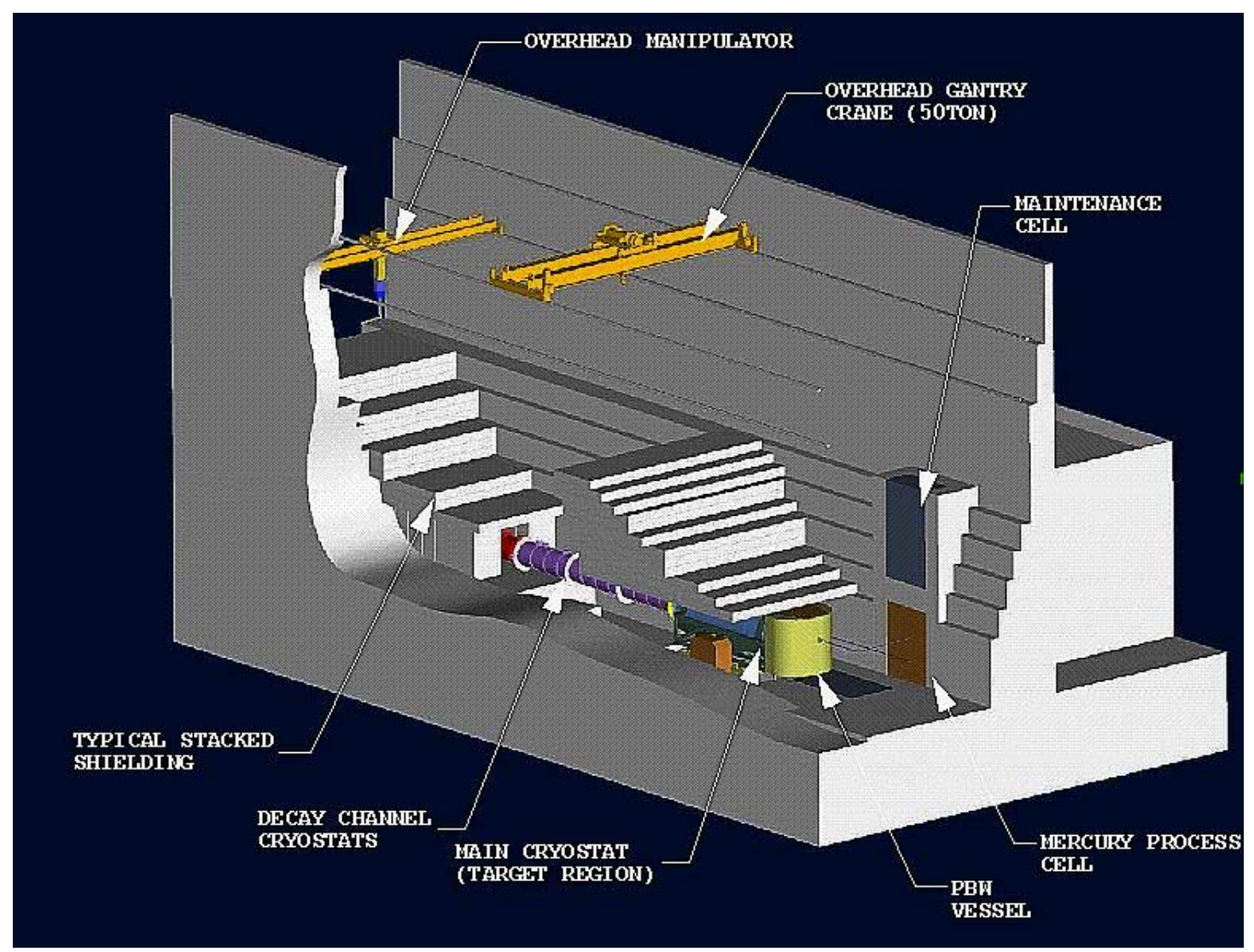

Figure 1: Cutaway view of the overall target facility. 


\section{TARGET SYSTEM AND BEAM ABSORBER}

The mercury-jet target system consists of the process flow loop, a replaceable nozzle assembly mounted in the bore of the iron plug magnet, a mercury containment vessel that is part of the decay channel downstream to $\mathrm{Z}=6.1 \mathrm{~m}$, and the beam absorber which is located at $70<Z<245 \mathrm{~cm}$. A dedicated hot cell that contains the flow loop components is located at the tunnel level. Figure 2 is a schematic diagram of the overall system.

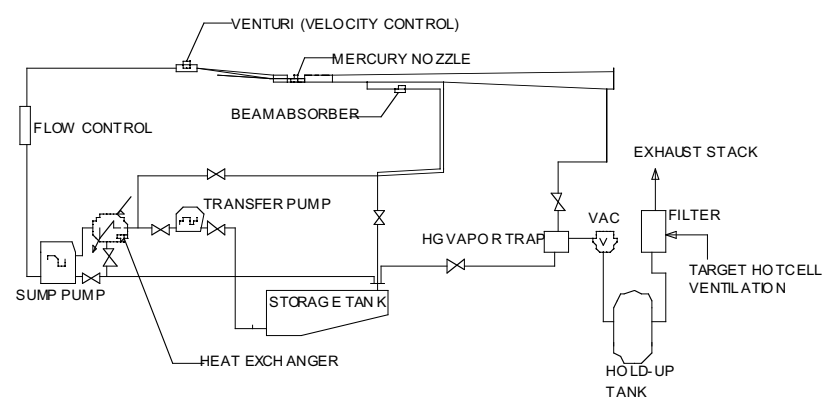

Figure 2: Target system and beam absorber schematic layout.

A 200-liter tank provides storage for the mercury when the system is shutdown or undergoing maintenance. The piping is sloped towards the storage tank, and the elevation of the sump pump, the heat exchanger, the beam absorber pool, and the storage tank are arranged so that the mercury level can be easily controlled among the components. Various valves are used to isolate portions of the system for storage, flow, or drainage into the storage tank, and drainage is by means of gravity. The system components are located in the target hot cell and are arranged to be accessible by wall-mounted manipulators.

There are drain lines from the sump pump, the heat exchanger, and beam absorber pool. In addition, there is a secondary drain/vent located at $\mathrm{Z}=6.0 \mathrm{~m}$. Its purpose is to extract and condense mercury vapors prior to maintenance operations that require opening the mercury containment in the capture/decay region. The vent line is connected in series to a mercury trap (condenser) and a vacuum scroll pump. The condensate is returned to the storage tank by means of a bypass line and the vacuum exhaust passes into the first hold up tank. Gases and mercury vapors are passed through a filter system that contains sulfur-treated charcoal filter modules, before passing into the facility ventilation exhaust.

Mercury vapors, and rare gas reaction products [4] are contained in the target/capture region by means of windows. The upstream inconel window is mounted on the target nozzle insert at the proton beam line axis; the downstream beryllium window is mounted to the vacuum vessel at $\mathrm{Z}=6.1 \mathrm{~m}$. Figure 3 shows the location of the beryllium window.

The average beam power deposited in the jet is $400 \mathrm{~W} / \mathrm{g}$ $(128 \mathrm{~kW})$ and the remainder of the $1 \mathrm{MW}$ proton beam power is deposited in the absorber. The bulk temperature rise of mercury in the absorber pool is $102^{\circ} \mathrm{C}$, well below the boiling point. However, this assumes homogeneous mixing occurs in the pool caused by the mercury jet that is "injected" into the pool at a rate of 2.4 liters/sec.

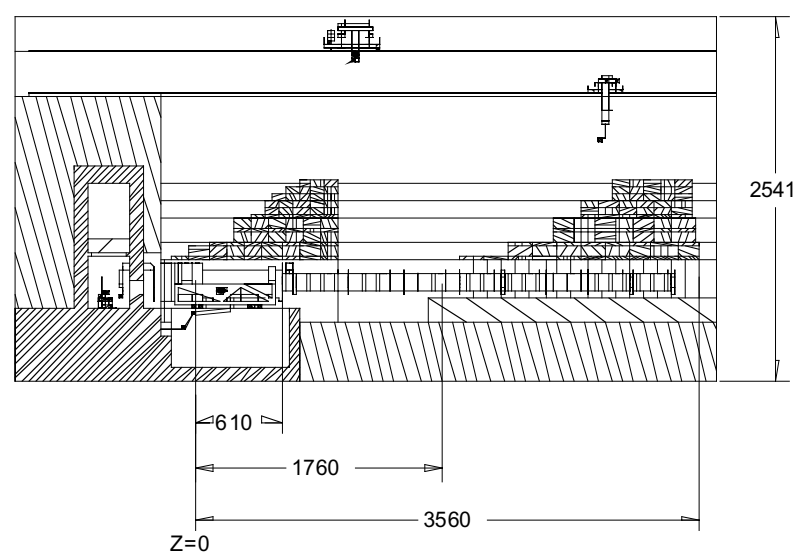

Figure 3: Side elevation of the facility geometry.

\section{TARGET SUPPORT FACILITY}

The geometry for the target support facility is defined around the intersection of the mercury jet, the proton beam, and the magnetic axis of the solenoid magnets. The proton beam interacts with the jet over a $30-\mathrm{cm}$ region so that the downstream interaction point is at $Z=0 \mathrm{~cm}$ and the upstream interaction point is at $Z=-30 \mathrm{~cm}$. The three axes intersect at $Z=-15 \mathrm{~cm}$. The locations of the coils and other components are measured from $Z=0$. The decay channel extends to $Z=35.60 \mathrm{~m}$, which is the facility interface with the first induction linear accelerator. Figure 3 shows the basic geometry of the facility.

The proton beam window is located at $\mathrm{Z}=-330 \mathrm{~cm}$ and is connected to a vacuum vessel enclosure with a removable section of beam pipe. This design permits the window assembly to be close to the target region, yet readily removable to replace the window or the mercury jet nozzle, or provide clearance for the replacement of the inner solenoid module should that ever become necessary.

It is important to keep in mind that virtually all of the components that make up the target and capture facility will be highly radioactive; therefore, replacing components after start-up operations must be done using remote handling equipment and tools. The development of the facility arrangement was based on considering the initial assembly and installation of the various subsystems, and also on modularization of components to simplify remote 
handling, and have minimal impact on the operating availability.

The solenoid magnets are located in the capture and decay tunnel of the support facility. Although they are considered to be lifetime components, the facility design is based on their remote replacement. The tunnel begins in the target region upstream of the proton beam window and extends to $\mathrm{Z}=35.6 \mathrm{~m}$. The first five solenoids (SC1-5) are contained in a common cryostat that extends to $\mathrm{Z}=6.1 \mathrm{~m}$. The cryostat is designed so that its inner shell is the outer shell of part of the tungsten-carbide shield. Therefore, there is a shield cylinder attached to the cryostat that is $16-20 \mathrm{~cm}$ thick and it contains inner rib supports to stiffen this cylindrical beam. The ribs are also partitions for the cooling flow-channels of the shield.

There is a separate module for the resistive magnets and shielding contained within the bore of SC1. It consists of an iron core, three resistive, water-cooled magnets (HC1-3), and tungsten-carbide shielding. The combination of these coils and SC1 provides the 20 Tesla field-on-axis in the target region. Figure 4 shows the resistive coil module along with the nozzle insert for the mercury jet.

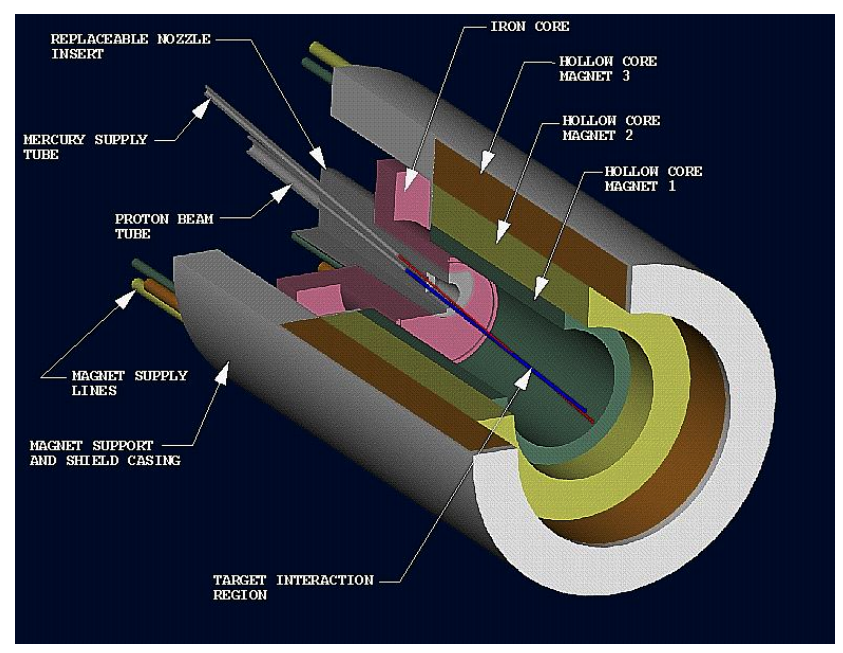

Figure 4: The resistive coils/shield module.

The magnets downstream of the main cryostat are twocoil solenoids contained in 4-m-long cryostats. They are protected from radiation damage with steel and water shielding.

The assembly and installation of the magnet system was the major consideration for determining the facility arrangement. The coil/shield modules are the heaviest and largest components and were the basis for establishing the building height and width, and for determining the crane capacity needed for installation operations and maintenance. The largest module weight is the tungstencarbide shield for SC4-5 at approximately 43 tons. A 50 -ton bridge crane with a $46-\mathrm{ft}$ span was chosen.

The solenoid magnets are designed to be lifetime components. However, they are configured for remote replacement in the event of failure since they will become highly activated, and since the ability to replace these is critical to the operation of the facility. Removal of any solenoid cryostat requires removing at least 24 shield slabs covering the tunnel. Each shield piece weighs 45 tons, and there is ample space on the crane hall floor to stack the shielding. Once the process of removing shielding is started, personnel access to the crane hall is not permitted and removal operations must be done remotely using the bridge-mounted manipulator system. The maintenance cell, located above the target hot cell, is configured to accommodate the cryostat modules for subsequent dismantling and waste disposal.

The facility shielding is designed to permit unlimited access to radiation workers in the crane hall. The shield material and thickness limit the dose rate at the crane hall floor to $0.0025 \mathrm{mSv}(0.25 \mathrm{mrem} / \mathrm{h})$. A Monte Carlo neutron, photon, charged particle transport code (MCNPX) using cylindrical geometry was prepared for neutronic calculations. The results show that the shield over the target region should be $5.8-\mathrm{m}$ thick and shielding over the decay channel should be 5.2-m thick.

\section{REFERENCES}

[1] http://www.cap.bnl.gov/mumu/studyii/report/TODO/ The-Report.pdf

[2] http://www.cap.bnl.gov/mumu/studyii/report/ Feasibility-I/Feasibility-I-fnal.pdf

[3] P. T. Spampinato et al., "Support Facility for a Graphite Target Neutrino Factory," ORNL/TM2000/153, August 2000.

[4] H. Ravn, CERN, private communication.

\section{ACKNOWLEDGEMENT}

This research was sponsored by the U.S. Department of Energy, under contract DE-AC05-00OR22725 with Oak Ridge National Laboratory, managed by UT-Battelle, LLC. 